\title{
USING ANALYTIC HIERARCHY PROCESS FOR THE EVALUATION OF GOVERNMENT PROJECTS
}

\author{
Kwok Yoong Fui* \\ Defence Science and Technology Agency \\ Singapore \\ E-mail: kyoongfu@dsta.gov.sg
}

\begin{abstract}
The Analytic Hierarchy Process (AHP) has been employed as a decision support tool in the evaluation of several major government tenders in Singapore in recent years. The AHP was found to be useful in helping organisations develop the goal of the project which was then manifested as key objectives which translate to the lower level criteria used for the evaluation of the proposals. It was challenging to implement AHP for these projects due to the varied nature of the projects, the diverse composition of each project team, the different interest of the stakeholders and the dissimilar organisational setup.
\end{abstract}

\section{Introduction}

The Analytic Hierarchy Process (AHP) has been used for the evaluation of several major government projects in Singapore in recent years. In this article, the following projects will be referred to in the discussion:

Integrated Resort project - This project entails the bidders to propose the overall concept in terms of the design, the functionalities and the programmes to maximise tourist influx and spending. A key element in the integrated resort is the allocation of a predefined floor area for the casino.

Motor Race Track project - This project requires the bidders to propose the overall plan to finance, design, develop and operate a permanent integrated motor race track and the associated facilities and infrastructure.

Broadband Network project - This project requires the winning bidder to build and operate a high speed broad band network to support the increasingly digital and globalised market place.

Airport Terminal Upgrading project. - This project requires the winning bidder to carry out upgrading work to the airport terminal with minimal disruption to airport operations, effect on tenants and inconvenience to airport users.

This article highlights some learning points from the use of AHP for the evaluation of these projects and discusses some of the challenges faced.

\section{Understanding the project objectives and developing the criteria early}

Regardless of the nature of the project, it was found crucial for the project team to understand the project objectives well at the onset. For some projects, this was done through a visioning workshop to solicit early input on the desire outcome from key stakeholders. This allowed the team to subsequently develop the necessary criteria in order to effectively carry out the evaluation at the later stages. Information obtained at the Request for Information stage was harnessed to evolve the criteria and the weights. Developing the criteria and weights ahead of the actual tender ensured that the

\footnotetext{
${ }^{*}$ Corresponding author
} 
necessary conditions and requirements were included in the tender documents. This had helped geared the bidders' proposals towards meeting some, if not all, the requirements of the project.

In the situation where the nature of a project was new to the organisation, it was not easy to define a clear goal right from the beginning. Such was the case for the Motor Race Track project. The intention was not to just build a race track like any other countries. The organisation in charge wanted to build a motorsports eco-system that could meet the key objectives of being the most preferred venue for motorsports events in the region, a centre of excellence for motorsports training and education and a catalyst for a sustainable and vibrant motorsports eco-system in the country. These high level objectives helped to define the goal better and were grouped under a criterion called Quality of Concept Proposal - which was given $80 \%$ of the weight. The other $20 \%$ went to Financial Sustenance and Risk to ensure that the winning bid has sufficient financial muscle to see through not only the project's design and development but also its operation in the next 25 years. Figure 1 shows the AHP for the Motor Race Track project.

To select a competent consortium to finance, develop $\&$ operate the motorsports hub $\&$ contribute to the development of a sustainable motorsports eco-system in Singapore

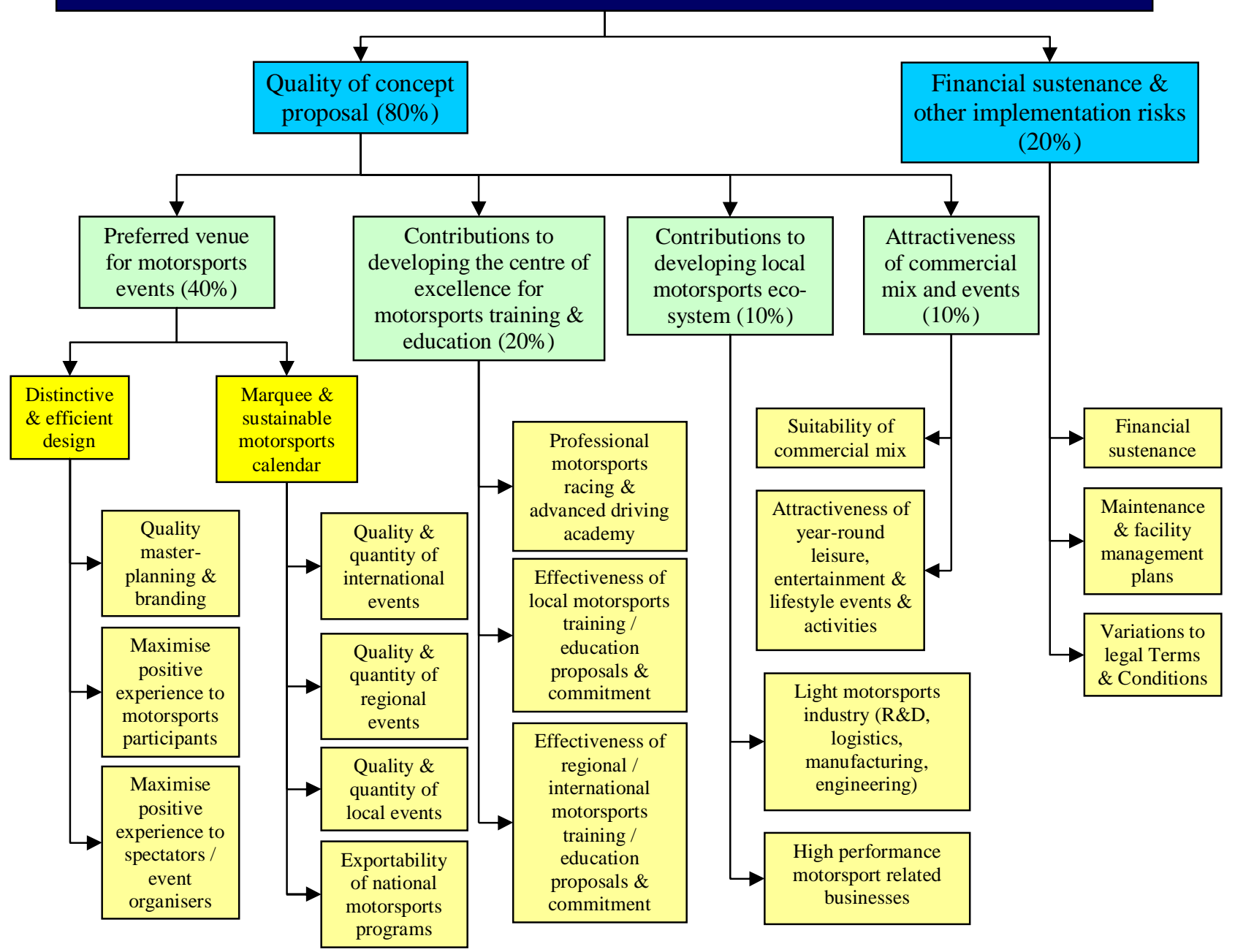

Figure 1. AHP criteria for the Motor Race Track Project 
For the Integrated Resorts project, the goal of the project was intentionally kept generic. The goal was simply stated as "To Maximise Economic Benefits for Singapore", which in turn was supported by the first level criteria of tourism appeal and contribution, architectural concept and design, development investment and strength of consortium. It could be argued that the architecture aspect was not a direct contributor to economic benefit and did not deserve a higher weight than investment. But it could not be denied that an iconic monument would have a more enormous drawing power for foreign dollars as compared with a run-of-the-mill structure. A weight of $30 \%$ was thus allocated to architectural concept and design. This was seen to be significant as the key objective of tourism appeal and contribution was only a mere $10 \%$ higher. Figure 2 shows the first level criteria of the Integrated Resort project.

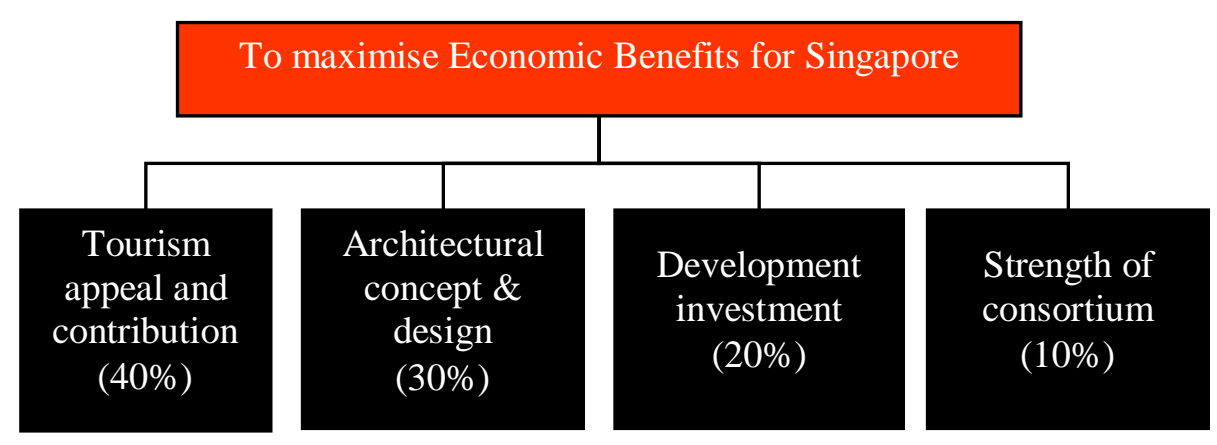

Figure 2. Goal and first level criteria for the Integrated Resort Project

\section{Having subject matter experts for each key objective}

For each key criterion or objective at the first level, a subject matter expert was usually identified to oversee the development of the sub-criteria and to carry out the subsequent evaluation for that criterion. For example, matters relating to finance matters and government grant were handled by the Finance Department of the organisation and the Ministry of Finance together. However the project manager of the project must have an overall view of the entire evaluation tree.

\section{Getting senior management on-board early and formation of relevant committees}

For a successful AHP evaluation, the committee who will eventually give the approval for the bidder selection must understand the basic mechanics behind AHP and must have faith in the process. To ensure this, a one to two-hour briefing session was organised to acquaint the senior management on the basics of AHP. This was done early during the tendering phase so that the committees had time to understand the process and would be more conversant of the criteria and the weights to be used for evaluation.

Several levels of committees were formed to manage the entire evaluation process - from carrying out the actual evaluation work to approving the award of tender. This ensured that adequate check and balance are in place and there were transparency and fairness in the evaluation process.

At the first level of the evaluation structure was the Tender Evaluation Team (TET) which did the actual evaluation. It comprised members from all the key stakeholder agencies, subject matter experts and consultants to ensure that all views were adequately presented, discussed, agreed upon and documented. The TET was chaired by a project director or project manager from the lead organisation. Usually the TET consists of several sub-groups, with each group managing one main branch of the AHP tree. 
The recommendations from the TET went to the Tender Approval Authority (TAA) for approval. For mega multimillion dollar projects, the TAA was chaired by a government minister. For projects that straddle across areas under the purview of different ministries, the TAA had to include the relevant ministers.

Between the TET and TAA, one or two committees were usually formed to endorse the recommendation, depending on the complexity and value of the projects. These were the Tender Working Committee (TWC) and the Tender Evaluation Committee (TEC). The TWC was usually chaired by the head of the lead organisation while the TEC was chaired by a Permanent Secretary (a post just below a minister). These two committees ensured that the evaluation was done diligently and fairly before the recommendation was put up to the TAA for approval.

\section{Handling different stakeholders}

The complexity of the evaluation increased with the number of diverse stakeholders in a project. For the Integrated Resorts project, there were several key stakeholders, such as the Tourism Board, the Ministry of Finance and the Urban Redevelopment Authority (URA) which was responsible for land development in Singapore.

Because of the diverse interest of these agencies, deciding on the weight for each criterion was a tedious process. The Tourism Board was interested in the facilities and programmes offered as these would have direct relationship with the projected number of tourists coming. The Ministry of Finance was interested in the economic returns and development investment. The URA had architecture supremacy as her prime objective. Although achieving excellence in any one of these areas would contribute eventually to the overall goal of the project, the proponent of each area would always try to maximise his influence on the goal through his respective area.

With these diverse views, the chairman of the evaluation team had to facilitate the evaluation process well and adopt a firm and even-handed approach in order to arrive at a weight distribution that was acceptable by all. In the event of an impasse, the chairman brought the case, on a timely basis, to a higher level forum for arbitration in order to move the evaluation process forward. It was not uncommon to arrive at the final form of the hierarchy after several weeks of intense deliberation.

\section{Releasing information to bidders}

Whether to release the evaluation criteria and weights to the bidders was a careful decision that had to be made for each project. The decision depended a lot on the project team's understanding of the bidders' profile, the nature of the project and the difference it would make to the outcome. For majority of the projects, only the first level criteria and the weights were made known to the bidders. This was deemed sufficient as the teams did not want the bidders to game their proposals to promise the best but have no assurance of effective delivery.

However for the Broadband Network project, the team decided to release all criteria down to the last level including the weights as the project was highly technical and adequate emphasis must be placed by the bidders on the key areas to ensure project success. The team felt that the risk of releasing this information was worth taking as there were only two equally reputable bidders at the end of the race who would likely deliver as promised. Knowing the criteria and the weights would help the bidders know exactly which areas were important in the project and hence place emphasis on these areas and submit a good proposal. 


\section{Using ratings approach for evaluation}

The pairwise comparison method was used for most of the evaluation. Some project teams felt that the Ratings Approach was more suitable even when the number of bidders was small. In this method, several bands were created and pairwise comparison was done only on these bands and not on the bidders, hence effectively reducing the number of comparisons needed.

The number of bands used typically ranges from four to six depending on the resolution desired. Having too few bands could result in most or all the bidders falling into one band, hence crippling the differentiation amongst the different bidders. A four-band rating was used for the Motor Race Track project. The four bands were tagged to Excellent, Good, Fair and Poor. Tables 1 to 3 show an example of how the bandings were used in scoring the criterion "Provision of Facilities".

Table 1. An example of the four-band used for the evaluation of "Provision of Facilities"

\begin{tabular}{|l|l|}
\hline Band & Description \\
\hline Excellent & $\begin{array}{l}\text { The bid provides for all the "Specified Facility" elements, are explained in detail, } \\
\text { are well defined and provides a high degree of confidence that the bid will deliver } \\
\text { all the facilities that will satisfy the requirements of the Invitation-To-Tender (ITT) } \\
\text { briefing documents. }\end{array}$ \\
\hline Good & $\begin{array}{l}\text { The bid provides for all the "Specified Facility" elements, are explained sufficiently } \\
\text { to provide confidence that the bid will deliver all the facilities that will satisfy the } \\
\text { requirements of the ITT briefing documents. }\end{array}$ \\
\hline Fair & $\begin{array}{l}\text { The "Specified Facility" elements to be provided are poorly detailed and the bid } \\
\text { does not provide confidence that it will deliver all the facilities that will satisfy the } \\
\text { requirements of the ITT briefing documents. }\end{array}$ \\
\hline Poor & $\begin{array}{l}\text { The "Specified Facility" elements to be provided are missing, substantially } \\
\text { incomplete or insufficient to provide confidence that the bid will deliver all the } \\
\text { facilities that will satisfy the requirements of the ITT briefing documents. }\end{array}$ \\
\hline
\end{tabular}

Table 2. Pairwise comparison of the four bands

\begin{tabular}{|l|c|c|c|c|}
\hline Provision of Facilities & Excellent & Good & Fair & Poor \\
\hline Excellent & & 3 & 6 & 9 \\
\hline Good & & & 5 & 7 \\
\hline Fair & & & & 3 \\
\hline Poor & & & \\
\hline
\end{tabular}

Table 3. Weights assigned based on the above pairwise comparison

\begin{tabular}{|l|c|}
\hline Bands & Weights \\
\hline Excellent & 1.000 \\
\hline Good & 0.518 \\
\hline Fair & 0.156 \\
\hline Poor & 0.075 \\
\hline
\end{tabular}


The Ratings Approach was also found useful for cases where the number of bidders was large. For such cases, a two-stage approach was adopted. In the first stage, the bidders were broadly categorised into bands using the Ratings Approach, based on whether the proposals were able to meet the baseline requirements and on the bidders' financial strength and track records. Bidders who cleared the first stage were then channeled to the second stage where pairwise comparison was used for the detailed evaluation.

\section{Considering costs}

For tender evaluation, AHP was used for the evaluation of proposals based on specifications. The cost of the proposals was considered separately. The treatment of cost was considerably different for different projects depending on the nature of the project.

For the Airport Terminal Upgrading project, the cost consists not only of the construction cost charged by the contractor, but also the cost of relocation of airport tenants and the compensation paid to them for the temporary closure. However the net cost was offset by the reduction of operating cost due to the closure of some facilities. The eventual successful bidder was the one with the highest benefit to cost ratio.

For the Motor Race Track project, only bidders who had scored above a certain threshold value in the AHP evaluation progressed to the next stage where cost was then considered. The bidder with the lowest price wins the bid.

For the case of the Integrated Resort project, there was no cost consideration as the price of the land was fixed by the government. Evaluation was based purely on the attractiveness of the proposals to maximise economic benefits for the country.

For the Broadband Network project, again there was no direct cost incurred to the government. One of the criteria used in the AHP evaluation was "Level of Government Grant". The more grant a bidder asked for, the less weight he would get.

\section{Conclusion}

The versatility of AHP has enabled it to be adopted for the evaluation of a wide range of projects. By observing some basic rules and using the appropriate evaluation approach, selecting the best system has been made easier and more objective.

\section{REFERENCES}

The information in this paper is drawn from internal reports of the projects mentioned which are not made available to the public. 